\title{
OS NOVOS MUSEUS E A ESTÉTICA NA PÓS-MODERNIDADE
}

\author{
THE NEWS MUSEUMS AND AESTHETICS IN POST-MODERNITY
}

\author{
Marcel Ronaldo Morelli de Meira'
}

DOI: https://doi.org/ | 0265 I 2/museologia. v7i | 4 . 18396

\section{RESUMO}

Esse artigo considera a eclosão dos novos museus como sintomática da cultura pós-moderna iniciada nos anos 1970. Toma como referência o Centro George Pompidou, em Paris (1977), considerado o marco inaugural da dita cultura dos museus, além do Guggenheim Bilbao (1997), tomado aqui como o principal exemplo da arquitetura icônica e midiática dos museus contemporâneos. $A$ arquitetura icônica dos novos museus, observada inicialmente no exemplo do Centro Georges Pompidou e, posteriormente, no Guggenheim Bilbao, é compreendida como emblemática do esgotamento da arquitetura moderna, marcado pela perda de sua função prospectiva, e da espetacularização dos museus na chamada pós-modernidade.

\section{PALAVRAS-CHAVE}

Museus; Arte; Arquitetura; Estética; Pós-modernidade

\begin{abstract}
This papper considers the emergence of the new museums as symptomatic of the postmodern culture begun in the 1970s. It is based on the George Pompidou Center in Paris (1977), considered the inaugural landmark of this museum culture, as well as the Guggenheim Bilbao (1997), taken here as the main example of the iconic and media architecture of contemporary museums. The iconic architecture of the new museums, seen initially in the example of Georges Pompidou Center and, later, in the Guggenheim Bilbao, is understood as emblematic of the exhaustion of modern architecture, marked by the loss of its prospective function and the spectacularization of museums in called postmodernity.
\end{abstract}

\section{KEY-WORDS}

Museums; Art; Architecture; Aesthetic, Postmodernity

A concepção de museus que vigorou durante a primeira etapa do século XX foi marcada, sobretudo, pelo pensamento arquitetônico modernista. Tal proposta concebia os museus como elementos neutros, partindo do conceito

\footnotetext{
' Graduado em Ciências Sociais pela Universidade Estadual de Londrina (2004), Mestre em Ciências Sociais pela Universidade Estadual de Londrina (2009), Doutor em Filosofia pela Universidade de São Paulo (20I4), Pós-Doutor em Ciências Sociais pela Pontifícia Universidade Católica de São Paulo (20I8).
} 
de caixa ou contêiner indiferenciado, construído em concreto, aço e vidro, que procurava não intervir nas obras expostas, preservando em seu interior a autonomia da obra de arte. Processo oposto se dará nas décadas seguintes, com o advento dos novos museus que darão ênfase ao aspecto cenográfico de seu invólucro arquitetônico, enfatizando a volumetria e a escala do edifício enquanto elemento icônico e autorreferencial.

Em 1977, o Centro Georges Pompidou (Beaubourg), em Paris, surge como o grande marco na evolução do conceito moderno de museu, situando-se como a ruptura entre a tradição moderna dos museus neutros, marcados pela austeridade do edifício, e a tendência que nortearia sua concepção a partir da década de 1980, ou seja, a do museu espetacular e de grande escala, ligado principalmente à cultura de massa e à sociedade de consumo afluente. Essa nova tendência foi diagnosticada, no calor da hora, pelo filósofo Jean Baudrillard (I99I) como sendo o "efeito Beaubourg". De acordo com a própria descrição do filósofo francês:

Com as suas redes de tubos entrelaçados e seu ar de edifício de exposições ou de feira universal, com sua fragilidade (calculada?), dissuasiva de toda mentalidade ou da monumentalidade tradicional [...]. Em rigor, o único conteúdo do Beaubourg são as próprias massas, que o edifício trata como um conversor [...] ou, exatamente como uma refinaria trata um produto petrolífero (BAUDRILLARD, 1991: 84-88).

Pode-se dizer, assim, que a crítica de Baudrillard evidencia essa nova concepção estética e arquitetônica que marcou os novos museus, a partir dos anos de 1980. Ao partir da concepção do edifício enquanto forma-rentista ou imagem-mercadoria, o museu tornou-se o principal protagonista das cidades contemporâneas. $O$ período, que se iniciou na França por volta de 1977 e culminou no final da década de 1990, mais precisamente no ano de 1997, no Guggenheim de Bilbao, tornou-se conhecido como a "cultura dos novos museus".

Nesse processo, as grandes redes mundiais de museus, incluindo instituições públicas como o Louvre, basearam seus projetos de expansão nas experiências tomadas em Paris e em Bilbao, num processo de "animação cultural" por meio da arquitetura, sobretudo no caso de Bilbao, onde a construção do Guggenheim foi peça-chave no projeto de revitalização econômica da cidade basca. É possível dizer, então, que os novos museus tornaram-se um dos principais agentes transformadores da dinâmica das cidades.

A crítica aos museus, contudo, não é recente. Ela pode ser observada no ensaio de Paul Valéry, $O$ problema dos museus, de 1923, no qual o autor declarou não ser um grande entusiasta de museus, pois, mesmo que muitos deles possam ser admiráveis, ainda assim, nunca são "deliciosos". Segundo ele, "as ideias de classificação, de conservação e de utilidade pública, que são justas e claras, têm pouca relação com as delícias" (VALÉRY, 1993:53). Há no museu, segundo Valéry, uma "estranha desordem organizada", em que cada obra busca a primazia do olhar do observador, ocorrendo uma fria confusão em meio a um tumulto de "criaturas congeladas", cada qual exigindo "a inexistência de todas as outras". Sua análise é a de que o fruidor acabe entorpecido em meio a tantas riquezas, referindo-se, sobretudo, ao excesso de obras no Museu do Louvre. Para Valéry (1993: 54), a ideia de museu se coloca, por fim, como um "sistema de justapor produções que se devoram umas às outras".

A oposição ao caráter opressivo dos museus pode também ser vista em uma das passagens da obra Fundação e manifesto do futurismo (I9II), de Fillipo 
Marinetti, na qual o autor caracteriza os museus como "cemitérios", proclamando-os idênticos a sepulcros "pela sinistra promiscuidade de tantos corpos que não se conhecem" (MARINETTI, 1980: 35). Essa caracterização futurista dos museus como "absurdos matadouros de pintores e escultores" pode ser comparada à descrição do museu feita por Valéry (1993), que o chama de "casa de incoerência”. Há, contudo, segundo Ricardo Fabbrini (2008), uma diferença entre ambas as concepções: se Marinetti decretava a morte dos museus "com violência arrebatadora e incendiária", Valéry não defendia tal abolição, embora os criticasse ao ver na "vertigem da mistura" de suas inúmeras salas um "suplício" infligido à arte do passado.

Nenhuma dessas posições, entretanto, permite compreender o problema da eclosão dos novos museus na contemporaneidade, em que a noção de fruição da obra acaba esbarrando na de entretenimento. Isso porque, na década de 1980 , mais precisamente a partir de 1977, com a inauguração do Centro Georges Pompidou, os museus passaram a ocupar um espaço cada vez maior na cultura e na experiência cotidiana, transformando-se em "paradigma-chave" das atividades culturais contemporâneas, conforme expressão de Andreas Huyssen (I 996). Essa transformação torna-se ainda mais evidente na arquitetura de seus edifícios, podendo-se até mesmo afirmar que o sucesso rentável de qualquer cidade passou a depender substancialmente dos atrativos dessas instituições.

A eclosão dos novos museus pode ser considerada, também, como sintomática da cultura pós-moderna dos anos 1980, em que os frequentadores das exposições passaram a procurar cada vez mais experiências ligadas aos grandes espetáculos e às chamadas diversões de massa, em vez da "apropriação meticulosa" da obra de arte. Huyssen (1996) constatou que a "museofobia" das vanguardas, por exemplo, foi uma insistente característica da cultura modernista, que atacava o museu enquanto "peso morto do passado", defendendo uma completa renovação do cenário artístico e cultural. Para o autor, foi justamente com as vanguardas - futurismo, dadaísmo, surrealismo e construtivismo - que se começou uma "luta radical" contra o museu. Essa luta teve início com a exigência do "fim do passado", por meio da destruição dos signos de representação da tradição e na defesa de um "futuro totalmente diferente". Huyssen (1996: 222) considera, no entanto, que, na passagem da modernidade para a pós-modernidade, o museu sofreu uma importante transformação, passando "de bode expiatório à menina dos olhos das instituições culturais". Essa transformação tornou-se ainda mais evidente na relação entre a arquitetura pós-moderna e os novos edifícios de museus. O papel do museu deslocou-se, então, de um "local conservador elitista" para o "museu como cultura de massa, como um lugar de mise-en-scène espetacular e de exuberância operística" (HUYSSEN, 1996: 223).

Huyssen (1996), entretanto, ressalta que o grande sucesso do museu como cultura de massa não deve ser confundido com as reivindicações feitas nos anos de 1960 pela democratização da cultura, já que, no atual cenário cultural, a antiga ideia de museu como "templo das musas" passou a ceder lugar a um espaço híbrido, "em algum lugar entre a diversão pública e uma loja de departamentos" (HUYSSEN, 1996: 224). Os novos museus surgem em uma nova perspectiva, na qual as exposições, como também a própria arquitetura, passam a corresponder a uma mudança no perfil dos frequentadores, que procuram cada vez mais, segundo Huyssen (1996: 224), por "experiências enfáticas, iluminações instantâneas, megaeventos e espetáculos de grande sucesso". Assim, é possível pensar a passagem da modernidade para a pós-modernidade à luz da transição entre a "museofobia" das vanguardas, observada em Valéry e Marinetti, 
e a "museomania" pós-moderna, observada em Huyssen.

A partir da década de 1970, começou a se desenvolver uma arquitetura pós-utópica, destituída de qualquer função prospectiva, uma vez que ela não se voltava mais para o futuro (FABBRINI, 2006). $O$ modernismo foi se exaurindo e perdendo seu ímpeto transformador, convertendo-se em formas lúdicas, autorreferentes e, por consequência, esvaziadas de todo poder de negatividade, dando origem ao chamado pós-modernismo. $O$ "populismo estético" apresentado pela arquitetura de Robert Venturi, por exemplo, como sugerido no título de seu livro Aprendendo com Las Vegas, possibilitou observar uma característica fundamental do pós-modernismo em geral: "o apagamento da antiga fronteira entre a alta cultura e a assim chamada cultura de massa", de acordo com Fredric Jameson (JAMESON, 1996a, p. 28). Em outros termos, destituídas as pretensões de transformação utópica do modernismo, "o que costumava ser estigmatizado como cultura de massa é agora admitido no circuito de um novo e ampliado domínio cultural” (JAMESON, 1996b, p. 88).

Na pós-modernidade, segundo Jameson (200lb), a produção estética passou a ser integrada à produção de mercadorias, de modo que a urgência da economia em produzir novas séries de produtos fez com que se enfatizasse cada vez mais a inovação estética e o experimentalismo, dando origem ao "pluralismo estilístico" - termo cunhado por Habermas. Assim, o que Jameson (200lb, p. I42) configura como pós-modernidade é "a supressão de tudo que esteja de fora da cultura comercial, a absorção de todas as formas de arte, alta e baixa, pelo processo de produção de imagens".

Enquanto a arquitetura moderna investia no caráter utópico de transformação radical do tecido urbano degradado em que se inseria (como nos altos pilotis de Le Corbusier), os edifícios pós-modernos, ao contrário,"celebravam sua inserção no tecido heterogêneo da paisagem do corredor comercial" (JAMESON, I 996b, p. 87). A partir de então, o historicismo pós-moderno passou a renunciar à pretensão de diferenciação radical e de inovação que caracterizou o modernismo arquitetônico. Essa nova situação, que os historiadores da arquitetura chamaram de "historicismo", é, segundo Jameson (I 996a, p. 45), a "canibalização aleatória de todos os estilos do passado, o jogo aleatório de alusões estilísticas".

Jameson (1996a, p. 30) compreende, entretanto, o pós-modernismo como "uma concepção histórica e não meramente estilística", estabelecendo uma distinção "entre uma visão do pós-modernismo como estilo e uma visão que procura apreendê-lo como uma dominante cultural do capitalismo tardio" (JAMESON, 1996a, p. 30). Nesse novo estágio, "a própria esfera da cultura se expandiu, coincidindo com a da sociedade de consumo, de tal modo que o cultural já não se limita às suas formas tradicionais, mas é consumido a cada momento da vida cotidiana" (JAMESON, 200 l b, p. I I 5). O espaço social, segundo Jameson (200 I, p. II5), por sua vez, "está agora completamente saturado com a cultura da imagem". Nesse processo, a arte e também a arquitetura se transformaram em imagem na pós-modernidade, sendo, portanto, inútil esperar delas alguma forma de negação à lógica de produção de mercadorias, já que toda beleza tornou-se "meretrícia, e todo apelo a ela, uma "manobra ideológica", mas nunca um "recurso criativo".

Jürgen Habermas (1987), por sua vez, compreende que a confiança que envolveu os arquitetos do início do século $X X$ no poder emancipatório da 
arquitetura se esgotou com o fim das vanguardas, considerando que $\circ$ fim do ideário da modernidade resultou no apagamento de qualquer exterioridade à forma artística. Destituída de sua função utópica, a arquitetura, para o teórico alemão, teria se distanciado de tal modo da práxis que seus efeitos não mais poderiam ser aproveitados para o "mundo da vida", no sentido de uma "reconfiguração da existência", ou mesmo no sentido aqui compreendido de uma estetização do real. Conforme Habermas (1987), nas diferentes vertentes da arquitetura pós-moderna: o "neo-historicismo" de Hans Hollein ou RobertVenturi; a "arquitetura teatralmente ultramoderna" de Peter Eisenman ou Michael Graves; ou a "arquitetura ecológica" e "vitalista" da construção anônima - que renega o potencial racionalista da arquitetura moderna -, tem-se um mesmo modo de conservadorismo político, uma "reação evasiva" que se identifica com a tendência "afirmativa" de que "tudo mais deve permanecer como está" (HABERMAS, I987, p. 124).

O fim do moderno, constatado por Jameson enquanto substituição da obra de arte individual pela mercadoria cultural, foi considerado por Habermas (I987, p. II5) um "gesto de despedida apressada", pois, em sua opinião, a modernidade artística insere-se em um longo processo que remonta ao lluminismo do século XVIII e que, portanto, não apenas está inconclusa como também ainda pode produzir efeitos emancipatórios. Nesse sentido, o objetivo de Habermas em salvaguardar a arquitetura moderna, de Mies van der Rohe, Le Corbusier e Walter Gropius, não parte de uma mera preferência estilística, mas da tentativa de preservar o projeto iluminista. Para o autor, não se poderia proclamar de modo irrefletido uma era pós-moderna, pois isso significaria a renúncia ao projeto da modernidade em invadir por meio da arquitetura a prática cotidiana. Com o fim da arquitetura moderna, ter-se-ia, portanto, a "morte da arte", na medida em que Habermas a vê como indissociável da ideia de "utopia”. Destituí-la desse espírito seria o mesmo que neutralizar a arte, reduzindo-a ao "belo" e ao “decorativo", tal como entendeu Jameson (200 la, p. 87), ou seja, o “abandono da arte da procura pelo absoluto e pela verdade e sua redefinição como uma fonte de puro prazer e gratificação".

Com base na compreensão de Huyssen (1991), não se deve, porém, associar essa arte e arquitetura pós-moderna a uma forma de "neoconservadorismo", no sentido atribuído por Habermas, ou mesmo a um decadente índice de criatividade no capitalismo tardio, tal como faz Jameson. Seria preciso, pois, segundo Huyssen ( 199 I), liberar a arte da sobrecarga de responsabilidades assumidas pelas vanguardas heroicas, o que implica a renúncia às "ambições políticas do modernismo", isto é, à responsabilidade de "mudar o mundo" ao qual se apegaram os artistas e arquitetos modernos. Em outras palavras, a arquitetura não compartilha mais do ethos de progresso cultural vanguardista, o que significa dizer que "não estamos destinados a completar o projeto da modernidade", nos termos de Habermas, mas que "nem por isso necessitamos cair na irracionalidade ou no frenesi apocalíptico" (HUYSSEN, I99।, p. 75). Huyssen considera que se deve resgatar o "potencial crítico" e de "oposição" no interior do próprio pós-modernismo, explorando suas possibilidades de abrigar em si "contradições produtivas".

Por essa via, pode-se compreender a arquitetura espetacular dos novos museus, observada de modo mais claro no exemplo do museu Guggenheim de Frank Gehry, como emblemática desse esgotamento da arquitetura moderna, 
marcado pela perda de sua função prospectiva, e do surgimento da chamada pós-modernidade. Nessa mesma direção, argumenta-se que tal arquitetura espetacular, como nos exemplos de museus que veremos a seguir, que acolhe uma multidão de usuários para se divertir, não possui nada de formador. Assim, a crença ainda presente em Walter Benjamin (1986) de que a "atenção distraída", que implica justamente a rejeição da contemplação estética, poderia transformar a relação do espectador com a obra através de uma renovação do corpo sensório, foi logo se exaurindo no curso dos novos museus inaugurados após o Centro Pompidou, pois se verificou que, ao fim dessa cultura do "recolhimento", ainda presente em Valéry, seguiu-se uma cultura da "hipermultidão", nos termos de Jameson (1996a).

Os novos museus se configuram, segundo Otília Arantes (1993), como um autêntico "emblema" das políticas de "animação cultural" produzidas pelos Estados capitalistas ocidentais, "no intuito de criar grandes monumentos que sirvam ao mesmo tempo como suporte e lugar de criação da cultura e reanimação da vida pública" (ARANTES, 1993: 240). Nesse processo, é como se as novas responsabilidades econômicas estivessem devolvendo aos indivíduos a "cidadania", através de atividades "lúdico-culturais" patrocinadas pelas grandes empresas. Esses novos museus se apresentam, segundo a autora, como "sucedâneos de uma vida pública inexistente". Isso porque, no atual estágio do capitalismo, a indústria cultural entrou em seu período "soft" ou “pós-industrial", pois, ao se pensar o que foi a indústria cultural dos anos 1950 e 1960, ver-se-á que o processo se inverteu: "À desestetização da arte [proposta pela vanguarda] segue-se um momento complementar de estetização do social, visível no amplo espectro que vai dos museus de fine arts aos museus de história da vida cotidiana" (ARANTES, 1993: 24I).

O contraponto mais imediato à fruição nos novos museus é a "experiência contraditória" do museu moderno, que, segundo Arantes (I993: 235), apresenta-se como "cenário absolutamente neutro, concebido para favorecer a contemplação da obra enquanto experiência individual". A abolição da experiência estética entre o visitante e a obra de arte, proposta pelo museu moderno, resolveu-se num "fetiche invertido", pois se coloca como "cultura do recolhimento administrada como um descartável” (ARANTES, 1993:240). Os próprios museus foram transformados na medida desse novo contingente de "visitantes consumidores" de uma arte que pretendeu alcançar cada vez mais a escala das massas. Essa estetização dos museus, segundo Arantes (1993), tornou-se presente naquilo que é mais claramente visível, ou seja, na própria arquitetura, que cada vez mais passou a se apresentar ela mesma enquanto obra de arte, fazendo com que longas filas se formassem na entrada dos museus, onde a atração principal não eram mais as obras do acervo, mas sua própria arquitetura.

Para Arantes (1993), enquanto a arquitetura moderna via na cidade a realização do ideal de uma "obra de arte total”, a "totalização" proveniente dessa arquitetura dos novos museus se deu num plano, sobretudo, simbólico,"cujo poder de contaminação seria de tal forma abrangente que acabaria por incluir nele, analogicamente, toda a realidade" (ARANTES, 1993: 240). Arantes faz referência, por exemplo, ao depoimento do diretor do Museu de Mönchengladbach, na Alemanha, projetado pelo arquiteto austríaco Hans Hollein, entre 1972 e I982:

Um dos abrigos a que se chega do hall de entrada incrustado na cidade é a lanchonete do museu. Por outro lado, este lugar profano abre para uma parede com uma grande janela quadrada, que forne- 
ce a vista de uma paisagem arquitetônica e natural verdadeiramente magnífica: uma igreja gótica numa colina, cercada de velhas árvores. A forma da janela enquadra esta vista, como se fora na realidade uma grande moldura pictórica. $\bigcirc$ modo de percepção que domina neste lugar é sem dúvida fundamental para o museu e é cuidadosamente elaborado. Isso transforma o mundo exterior num mundo estético, recuperado na perspectiva do museu (ARANTES, 1993: 245).

Tal descrição, segundo Arantes (1993), foi extraída de um estudo da historiadora Christa Bürger sobre o debate da pós-modernidade nos Estados Unidos. Nas palavras de Arantes, Bürger procura mostrar que a "cultura dos museus" tornou-se a expressão mais sintomática desse processo de estetização generalizada, pois, ao contrário dos museus didáticos, ainda projetados até os anos 1970, os novos museus, a partir da década de 1980, “optaram claramente por represar e desviar esse didatismo em favor de uma atitude hedonista, a seu ver, requerida pela sociedade de consumo" (ARANTES, 1993: 244).

Pode-se dizer, assim, que a experiência estética do museu de Hans Hollein estaria, então, vinculada a essa "percepção abrangente", na qual "todo o mundo" aparece como algo estético a partir do ponto de vista totalizador do museu. Sendo assim, não é apenas a obra de arte que o museu "neutraliza", tal como propôs Theodor Adorno (1998: 173) ao declarar que os museus "são sepulcros de obras de arte, pois testemunham a neutralização da cultura. Neles o valor de mercado não deixa lugar para a felicidade da contemplação", mas a própria "multiplicidade da vida urbana aí sintetizada", como descreve Arantes (1993). Isso ocorre porque o que está sendo posto em promoção é a própria cidade, que só se vende se for devidamente acompanhada de uma política de image-making (ARANTES, 2000). A cultura, consumida "na forma de refinamento artístico ostensivo", acabou sendo a melhor garantia para que o "clima dos negócios" fosse favorável.

Daí que, segundo Arantes (2000), a figura do arquiteto-urbanista reuniu em um único personagem o manager e o "intermediário cultural”. Esse planejamento de "gentrificação" das cidades pode ser observado, a princípio, nos exemplos dos grandes projetos de edifícios culturais promovidos pelo governo de François Mitterrand, na França, entre os anos de 1980 e 1990, no contexto do neoliberalismo e do desmanche do Estado Social de Direito. Mostra, dessa forma, que a renovação de Paris não partiu de um planejamento estratégico, mas do princípio de se fazer a cidade mediante show-cases. Assim, os elementos de gentrificação urbana se encontram todos inicialmente inseridos na providência tomada em Paris de "ampliação da indústria cultural que incorporava a cultura dos museus ao capitalismo da imagem" (ARANTES, 2000: 49). A conjunção de "empreendimento urbano" e "investimentos culturais" em escala industrial iniciou-se com o Centro Georges Pompidou, "invenção francesa” de 1977, considerado aqui como o ponto de partida dos novos museus.

Outro exemplo considerado paradigmático dessa "cultura dos novos museus" é o Museu Guggenheim na cidade de Bilbao, no País Basco, que era, até sua construção, uma "cidade degradada", como observa Arantes (2000), fruto de uma década de desindustrialização. $O$ planejamento estratégico da cidade parecia "patinar" até o momento em que o diretor da Fundação Guggenheim conseguiu um acordo com o prefeito da cidade para a construção de um edifício-símbolo que pudesse identificar Bilbao, tal como Sidney e seu teatro Opera House. $O$ resultado foi o museu projetado pelo arquiteto canadense, radicado 
nos Estados Unidos, Frank Gehry, "uma extravagante flor metálica de 200 miIhões de dólares (entre construção, franquia e acervo), mais de 30 mil metros quadrados, 70 metros de altura, a emergir do rio Nérvion" (ARANTES, 2000: 59), com o objetivo de exponenciar a oferta cultural da cidade.

Como observou Pedro Arantes (2008: I83), “a primeira tentativa de Frank Gehry de realizar uma fusão entre arquitetura e marketing deu-se com o projeto do Walt Disney Concert Hall, no centro de Los Angeles", em 1988, que "pretendia se destacar radicalmente de seu entorno urbano, cercado por imensas torres de escritório" (ARANTES, 2008: 183). O projeto "foi considerado inexequível pelas construtoras consultadas pela Disney, que suspendeu sua execução" (ARANTES, 2008: 183). Em 1997, contudo, Gehry inaugurou o que se tornaria o verdadeiro "emblema arquitetônico da globalização": o Museu Guggenheim de Bilbao. Considerado "surpreendente" por seu "aparato técnico e estético", mas também enquanto "estratégia rentista", o Guggenheim de Gehry foi capaz de conseguir uma "super-renda imagética de operação, enquanto outras cidades e corporações corriam atrás da mesma estratégia” (ARANTES, 2008: I83).

O último trabalho de Gehry para o Guggenheim foi a nova filial do museu em Abu Dhabi, capital dos Emirados Árabes. Nessa obra, Gehry teria trabaIhado sem qualquer restrição orçamentária, com o objetivo de superar Bilbao, de acordo com a solicitação de Thomas Krens, executivo da instituição, e dos “magnatas do petróleo”. De acordo com Arantes (2008: 191), o projeto se caracteriza por uma "repetição das fórmulas desconstrucionistas anteriores, mas em escala muito superior", participando da transição da renda petroleira para as novas formas de renda, tais como "parques temáticos, hotéis espetaculares, novos museus de grife, ilhas da fantasia, centros financeiros de lavagem de dinheiro etc." (ARANTES, 2008: 191).

Essa última fase de expansão dos novos museus pode ser observada nas cidades-Estado que compõem os Emirados Árabes Unidos. Segundo Guilherme Wisnik (2009: I37), trata-se de verdadeiros "oásis ultraocidentalizados que vêm se tornando o principal destino turístico de luxo e negócios do mundo". Responsável por uma das rendas per capita mais altas do globo, o emirado de Abu Dhabi, por exemplo, responde por $9 \%$ das reservas mundiais de petróleo "e ancora sua urbanização em museus-franquia de grife" (WISNIK, 2009: 137). Torna-se, então, impossível enxergar qualquer "miragem de emancipação" a partir desse caráter predatório das cidades, uma vez que em Dubai, afirma Wisnik (2009: 140), a "extração parasita de petróleo coincide com a colonização do território por mastodontes que petrificam a efemeridade da sociedade de consumo [...], esterilizando qualquer semente de urbanidade". Ao invés de apontar para alguma forma de emancipação, o gigantismo dessas cidades-resort é emblemático: de um "mundo que se autoconsome por cima e por baixo do solo simultaneamente, pois é exatamente uma 'indústria' que financia a outra (o petróleo e o turismo)" (WISNIK, 2009: I40).

Pode-se, portanto, compreender a proliferação dos novos museus, que vai do Beaubourg de Paris (1977), passando pelo Guggenheim de Bilbao (1997) até sua nova fase de expansão rumo ao Oriente Médio nos anos 2000, com os projetos de franquia do Guggenheim e do Museu do Louvre em Abu Dhabi, como decorrência do esgotamento da arte no sentido proposto pelo modernismo. Em outros termos, isso significa que o projeto de "democratização cultural" teria se resolvido no Beaubourg e, por conseguinte, na "cultura dos novos museus", em sentido contrário ao visado pelas vanguardas, ou seja, esse "consumo cultural extravagante", sintomático nos novos museus, acabou, de acordo com 
Fabbrini (2008), produzindo uma "estetização do social”.

A ideia da "sociabilidade estilizada" no interior dos novos museus remonta à inauguração do Beaubourg, identificada por Baudrillard (I991:92) como sintoma de uma nova modalidade de fruição das obras: "As pessoas têm vontade de pegar tudo, pilhar tudo, comer tudo: ver, decifrar, contemplar - aprender não as atinge". O sucesso do Beaubourg seria, então, aparente, na medida em que essa "invasão já não tem qualquer medida comum com o que se propunha como cultura enquanto 'lugar de segredo, de sedução, de iniciação', de 'uma troca simbólica restrita e altamente ritualizada"” (BAUDRILLARD, I991: 85). É, portanto, o mesmo que sua "negação radical, em seu excesso e em seu próprio êxito" (BAUDRILLARD, I 991: 87). A aposta no valor de exibição da arte no museu teria então contribuído para a "implosão do social" e para o "desaparecimento da cultura”. No Beaubourg, visto por Baudrillard (I99I), não apenas a inflação das obras provoca a deflação de sentido, mas os próprios visitantes dissolvem-se na multidão, que impossibilita qualquer tipo de recolhimento diante das obras. Trata-se, nos termos do autor (1991: 89), de espaços de "simulação operacional da vida social”, ou, como diz Otília Arantes (1993:24I), são "grandes cenários de uma sociabilidade fictícia acrescida das obras devidamente neutralizadas".

É importante considerar, contudo, de acordo com Fabbrini (2008), que essa "maratona de museus" assumiu diversos ritmos nos últimos anos devido às alterações ocorridas na conjuntura econômica internacional e na política cultural de diversos países, sobretudo após a retração da economia e do turismo que se seguiu ao ataque ao World Trade Center, em Nova York, em 200 I. Pode-se localizar o início dessa crise ou desaquecimento dos novos museus justamente a partir desse atentado terrorista, com a decorrente retração do turismo internacional e seu posterior aprofundamento causado pela crise financeira internacional iniciada em 2008. A partir de 2008, como é possível verificar, ocorreu uma reorientação na cultura de museus espetaculares, com o surgimento de museus marcados por certa economia de meios quanto à forma arquitetônica, pela contenção orçamentária e pela preocupação ecológica. Mesmo nos novos projetos de museus espetaculares, valorizam-se formas de construção menos predatórias, ditas "sustentáveis", como o Museu do Amanhã, no Rio de Janeiro, cujo projeto é assinado pelo arquiteto espanhol Santiago Calatrava.

Assim, a arquitetura icônica impulsionada pelo Guggenheim de Bilbao no final da década de 1990, denominada pelo crítico Luíz Fernández-Galiano (2009b) como a "arquitetura do otimismo", não é mais a tônica com o "desabamento econômico de 2008”. O boom do sistema imobiliário fez com que a arquitetura assumisse a centralidade das cidades, encontrando no museu basco a "confiança na capacidade da arquitetura emblemática, simbólica, para reconstituir a cidade por objetos de arquitetura como motores turísticos e de branding urbano" (FERNÁNDEZ-GALIANO, 2009b, p. 8I). No entanto, Fernández-Galiano (2009b, p. 8I) reconhece que "agora nos encontramos em uma conjuntura muito difícil e complicada", pois o que "temos vivido nos últimos anos são frutos tardios dessa etapa de grande confiança e otimismo". O museu como megaevento foi resultado, portanto, de um otimismo acrítico frente ao futuro das cidades.

Nessa direção, pode-se perguntar se a própria arquitetura teria perdido a propriedade que lhe permitia operar como crítica da sociedade capitalista ou, ainda, se seria possível uma arquitetura crítica que contribuísse para o desenvolvimento de novas sociabilidades no espaço urbano. Muitas dessas questões se 
apresentam a partir do arco de problemas levantados pelos novos museus desde os anos de 1970. Não existe, na verdade, nenhuma resposta fácil ou simplificadora, pois, ao encontrar seu lugar, outras áreas se iluminam para a resolução de novos problemas. O que está claro, porém, que é,"sobretudo em momentos como este, de crise, que se apresenta a chance de mudar as coisas" (WISNIK et al., 20I3). Daí, o nosso otimismo.

\section{REFERÊNCIAS}

ADORNO, T. Museu Valéry Proust. In: Prismas: crítica cultural e sociedade. São Paulo: Ática, 1998. p. 173-185.

ARANTES, O. Uma estratégia fatal: a cultura nas novas gestões urbanas. In:VAINER, C.; MARICATO, E. (orgs.). A cidade do pensamento único: desmanchando conceitos. Petrópolis:Vozes, 2000. p. II-74.

. Os novos museus. In: O lugar da arquitetura depois dos modernos. São Paulo: Edusp, 1993. p. 23 I-246.

ARANTES, P. O grau zero da arquitetura na era financeira. Novos Estudos CEBRAP, São Paulo, n. 80, p. 175-95, mar. 2008

BAUDRILLARD, J. O efeito Beaubourg. In: Simulacros e simulação. Lisboa: Relógio d'Água, 1991. p. 8I-96.

BENJAMIN,W.A obra de arte na era de sua reprodutibilidade técnica. In: Magia e técnica, arte e política: ensaios sobre literatura e história da cultura. São Paulo: Brasiliense, 1986. p. 165-96.

FABBRINI, R.A fruição nos novos museus. Especiaria: Cadernos de Ciências Humanas, Ilhéus, v. I I, n. 19, pp. 245-268, jan./jun. 2008.

. O fim das vanguardas. Cadernos da Pós-Graduação do Instituto de Arte, Unicamp, Campinas, ano 8, n. 2, pp. I I I-29, 2006.

FERNÁNDEZ-GALIANO, L. Firmitas, utilitas e venustas. Revista $A+U$, Tokyo, n. I8I, p. 80-84, abr. 2009.

HABERMAS, J.Arquitetura moderna e pós-moderna. Novos Estudos CEBRAP, São Paulo, n. I8, pp. II5-I24, set. 1987.

HUYSSEN,A. Escapando da amnésia: o museu como cultura de massa. In: Memórias do modernismo. Rio de Janeiro: Editora da UFRJ, 1996. p. 222-255.

. Mapeando o pós-moderno. In: HOLLANDA, H. B. (org.). Pós-modernismo e política. Rio de Janeiro: Rocco, 1991. p. 15-80.

JAMESON, F."Fim da arte" ou "fim da história"?. In: A cultura do dinheiro: ensaios sobre a globalização. Petrópolis, RJ:Vozes, 200 la. p. 73-93.

A transformação da imagem na pós-modernidade. In: A cultura do dinheiro: ensaios sobre a globalização. Petrópolis, RJ:Vozes, 200 Ib. p. 95 - I 42. A lógica cultural do capitalismo tardio. In: Pós-modernismo: a lógi-

ca cultural do capitalismo tardio. São Paulo: Ática, 1996a. p. 27-79. . Teorias do pós-moderno. In: Pós-modernismo: a lógica cultural do capitalismo tardio. São Paulo: Ática, 1996b. p.80-90.

MARINETTI, F. Fundação e manifesto do futurismo. In: BERNARDINI,A. F. (org.). O futurismo italiano: manifestos. São Paulo: Perspectiva, 1980. p. 3 I-36. VALÉRY, P. O problema dos museus. Revista MAC, São Paulo, n. 2, p. 53-55, nov. 1993. 
WISNIK, G. Do petróleo ao resort. In: Estado crítico: à deriva nas cidades. São Paulo: Publifolha, 2009. p. I37-I40.

WISNKI, G. [et al.]. Cidades em processo. Folha de S.Paulo. Caderno llustríssima,09 out. 20 I3.Disponível em:<http://folha.uol.com.br/ilustrissima/20 I3/ I0/I35 I80 I -as-cidades-em-processo.shtml>. Acesso em: 4 jun. 2013. 